\title{
The Converter Command for the Doubly-Fed Induction Generator with Variable Speed used in the Wind Power Production
}

\author{
Abdelhadi El Moudden \\ Team Analysis and Command \\ of Electrical Energy Systems \\ (ACSEE) \\ LISER - Laboratory \\ ENSEM, Hassan II University \\ Casablanca, Morocco
}

\author{
Abdelali Aarib \\ Team Analysis and Command \\ of Electrical Energy Systems \\ (ACSEE) \\ LISER - Laboratory \\ ENSEM, Hassan II University \\ Casablanca, Morocco
}

\author{
Abdelhamid Hmidat \\ Electrical Systems Team \\ ENSEM, Hassan II University \\ BP 8118, Oasis, \\ Casablanca, Morocco
}

\begin{abstract}
This paper presents a global and optimal environment of the electro-mechanical conversion chain using the doubly-fed induction generator (DFIG) in wind turbines having an active power in the stator of the order of Megawatts (MW).

The establishment of the diverse models of electric parameters and the development of the methodological tools available in the environment MATLAB/Simulink are interpreted [1]. The main components of the chain of conversion are modelled and the DFIG makes the object of a particular attention as for its sizing.

Analytical and numerical methods are proposed to carry out the optimal design of the entire drive including DFIG, the multiplier mechanical speed and power converter. The implementation of the environment is illustrated by solutions associated with different overall design requirement specifications including the distribution of active and reactive stator powers on the DFIG [2]. The results show that there are different solutions as the original topology is presented dimensionally. The goal is to optimize the quality of energy generated by wind by manipulating the sizes of the active and reactive power as needed. The approach of the control of converters AC-DC-AC is used [3]. The method used is to adjust the stator reactive power so that the machine side converter and inverter supply side will be bidirectional, to adjust the wind speed to that of the doubly-fed induction generator, which is very favourable for energy production in wind systems. The results of the simulation will be presented in MATLAB/Simulink, as well as related interpretations.
\end{abstract}

\section{Keywords}

DFIG, PWM, Rectifier, Wind Energy, Wind Turbine, Converters, Modeling, MATLAB/Simulink, Continuous bus, Converters (AC-DC-AC), Park.

\section{INTRODUCTION}

Wind generation tends to play an important role in the total generation mix of the future power system due to the need to decrease carbon dioxide $\left(\mathrm{CO}_{2}\right)$ emissions resulting from electricity production. This is due to the existence of no exploited wind resources and to the fact that it is a clean and environmental friendly energy source with a reduced cost of installation and maintenance the wind turbines based on the doubly-fed induction generators (DFIG) is an attractive solution for the wind power generation [4]. Where the rotor is fed by a variable AC voltage sources, which can be controlled in frequencies according to variable speed of the rotor shaft due to the variation of speed wind. Then the electric power at constant frequency is simply provided from the stator of the DFIG [5]. These machines are a bit more complex than the squirrel cage induction machine. In spite of the presence of rubbing contacts (rings-brushes), a main advantage of the doubly-fed induction machine is the accessibility of its both armatures from which the power flow control can be easily occurred between machine and grid. The objective of this work is the modelling, simulation and decoupled control of active and reactive powers for a DFIG [6]. The modelling will allow determining theoretical operating characteristics of the DFIG and studying the influence of the parameters on the operation of the DFIG. The main parameters are the sliding $S$, the stator active power $P_{S}$, and the stator reactive power $Q_{s}$. This decoupling powers control keeps the power factor very interesting [7].

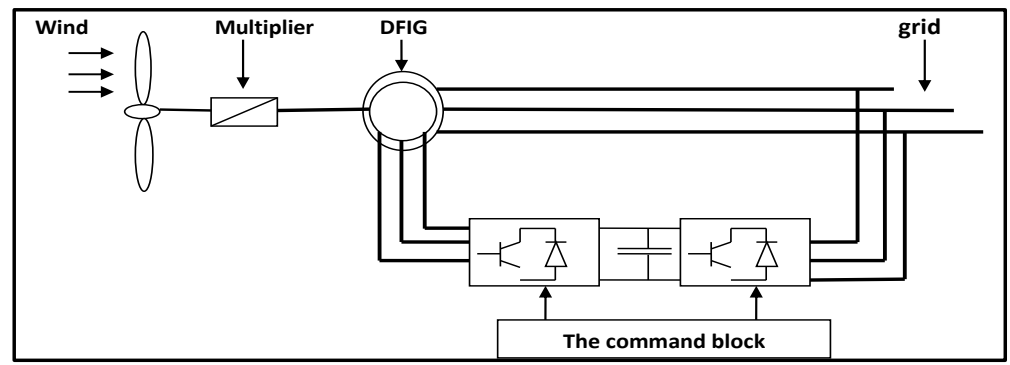

Fig 1 : DFIG in the wind energy conversion chain 


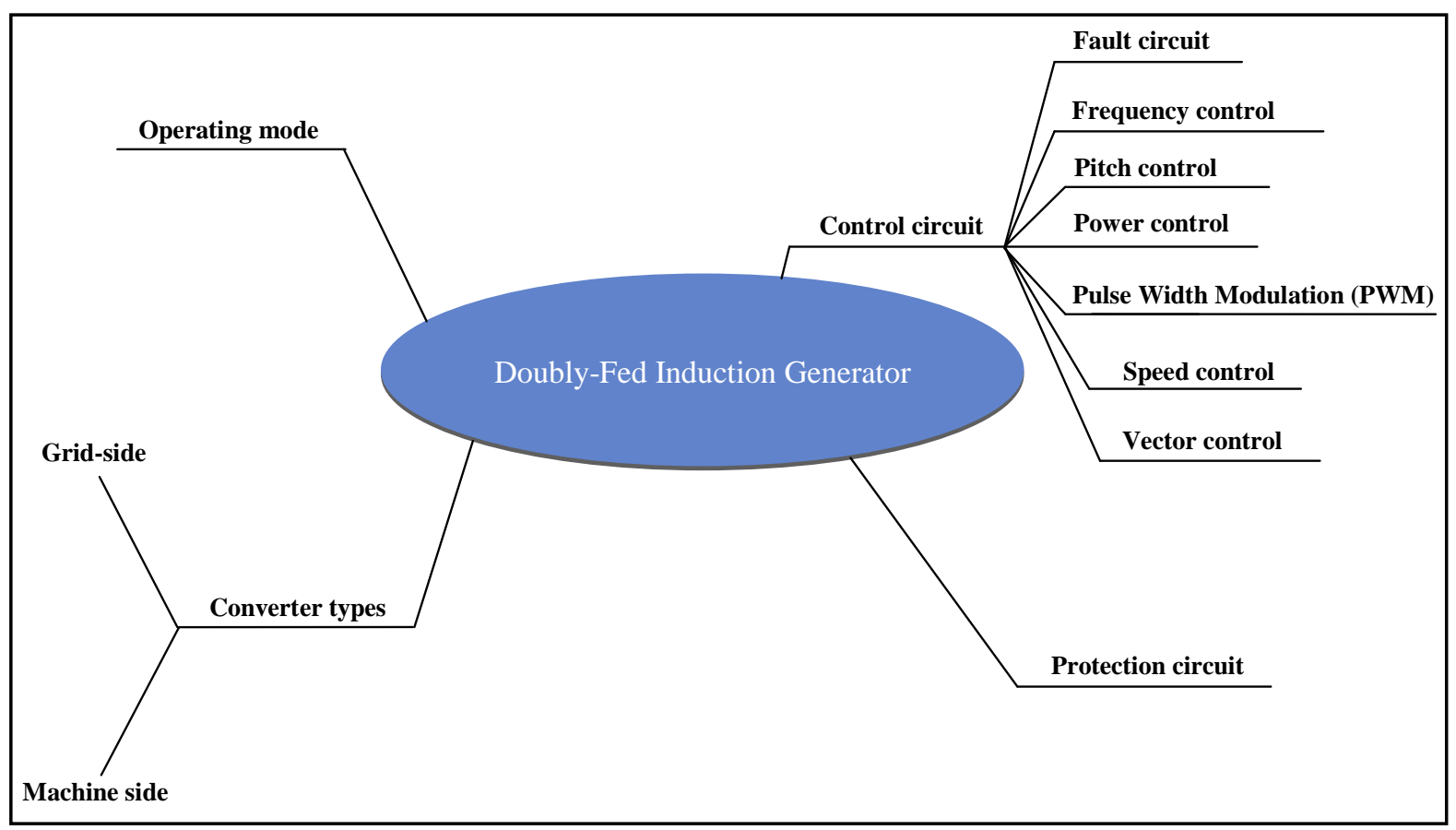

Fig 2 : Synoptic diagram of the DFIG wind turbine [21]

The stator winding is connected directly to the $50 \mathrm{~Hz}$ grid while the rotor is fed at variable frequency through the AC/DC/AC converter. The DFIG technology allows extracting maximum energy from the wind for low wind speeds by optimizing the turbine speed, while minimizing mechanical stresses on the turbine during gusts of wind. Another advantage of the DFIG technology is the ability for power electronic converters to generate or absorb reactive power.

\section{THE CONCEPT OF THE ACTIVE POWER}

The active power of the stator is always flowing into the grid, independently of the operation state, whereas the machine operates as a motor (sub-synchronism operation) when absorbing power [8], while the machine operates as a generator (hyper-synchronism operation) when supplying power. By neglecting the power losses, the relation between the rotor power $\left(P_{r}\right)$ and the stator power $\left(P_{S}\right)$, through the slip $(S)$ is given by [16] :

$$
P_{r}=S P_{S}
$$

Where $S$ is defined as the slip of the machine, which is given by :

$$
S=\frac{\text { synchronous speed }- \text { Rotor speed }}{\text { synchronous speed }}
$$

Therefore, the net power $P_{\text {net }}$ that is generated from both stator and rotor side can be expressed as :

$$
P_{\text {net }}=P_{S}-P_{r}=P_{S}-S P_{S}=P_{S}(1-S)
$$

When the slip $S$ is negative, the machine will operate in the hyper-synchronous operation state (as a generator), while the machine will operate in the hypo-synchronous operation state (as a motor) when the slip $S$ is positive, in this case, the rotor speed is slower than the synchronous speed. By this configuration [9], the wound rotor induction generator delivers directly the $\frac{2}{3}$ of its rated power to the grid through the stator windings, while it delivers $\frac{1}{3}$ of its rated power through the rotor windings via the converters [16].

\section{ROTOR-SIDE CONVERTER (RSC) CONTROL OF THE DFIG}

The rotor-side converter controller is used to control independently the stator voltage alternatively (reactive power and output active power of the wind turbine [17] [18]). Since the converter operates in a stator-flux q-d reference frame, the rotor current is decomposed into an active power $(q-$ axis $)$ and a reactive power $(d-$ axis $)$ component. When the wind speed change, the active and reactive power (or voltage) of the generator will also change.

\section{GRID-SIDE CONVERTER (GSC) CONTROL OF THE DFIG}




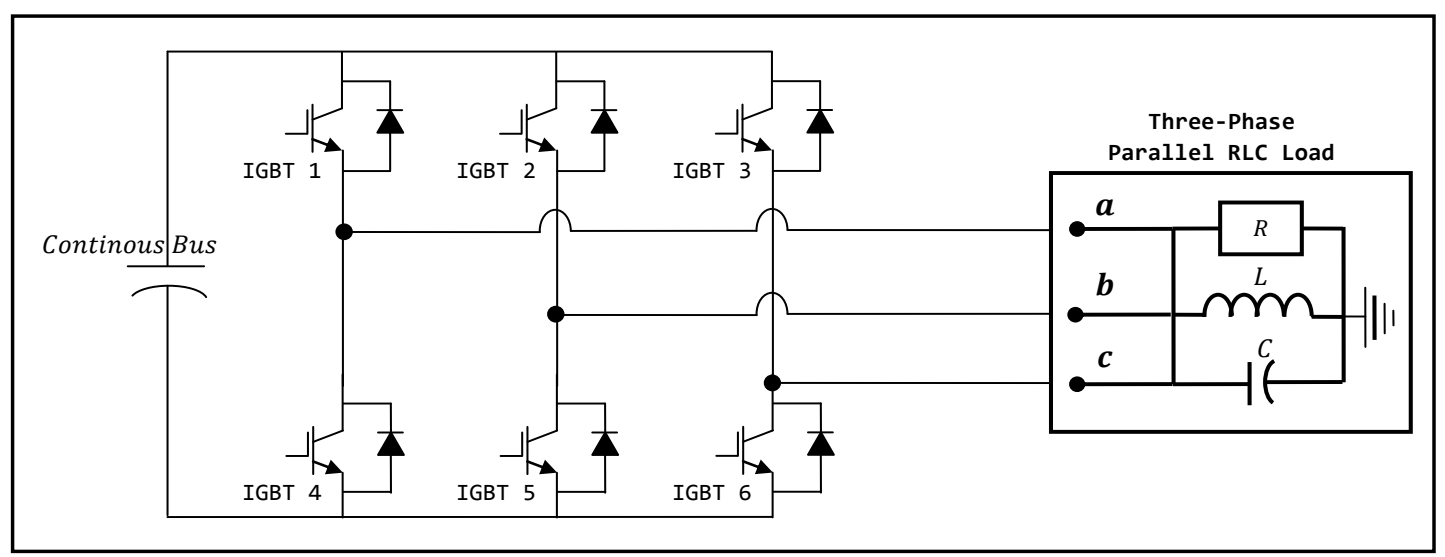

Fig 3 : Simulink model of the grid-side converter

The role of the grid-side converter is to control the DC-link voltage (Voltage in the borders of the capacity which represents the continuous bus) by maintaining it constantly and it is used to generate or absorb reactive power. The DClink voltage is used as well, with the $q-d$ reference frame oriented along the stator currents and stator voltages, enabling independent control of the active and reactive power flowing between the grid and the converters. The decoupling and compensation procedures of a typical grid-side converter control [10]. The difference between these two values $\left(V_{d c}\right.$ and $V_{d c-r e f}$ ) will go to two Proportional-Integral (PI) controllers which are used to generate the required value of $d$-axis stator voltage $\left(V_{d s}\right)$. Similarly, the difference between the actual reactive power $\left(Q_{S}\right)$ and reference value $\left(Q_{s-r e f}\right)$ will go to another two PI controller to generate the required value of the $q$-axis stator voltage $\left(V_{q s}\right)$ [28]. These desired $q-d$ voltages $\left(V_{r d-r e f}\right.$ and $\left.V_{r q-r e f}\right)$, the outputs of both (PI) controllers, are transformed from the $q-d$ frame into the $a b c$ frame to fire the IGBTs [19].

\section{PULSE WIDTH-MODULATED CONVERTER}

The back to back converter consists of one Pulse Width Modulated (PWM) rectifier and one inverted PWM rectifier with a DC-link capacitor in between as shown in figure 4 . The only difference between the inverter and rectifier is the definition of the power sign. The rotor side of the converter is modulated to give a sinusoidal line current with a chosen frequency. The DC-link voltage is regulated and kept constant by controlling the power flow through the grid side of the converter. The rectifier and inverter consists of three transistor half-bridges each built up by semiconductors [28].

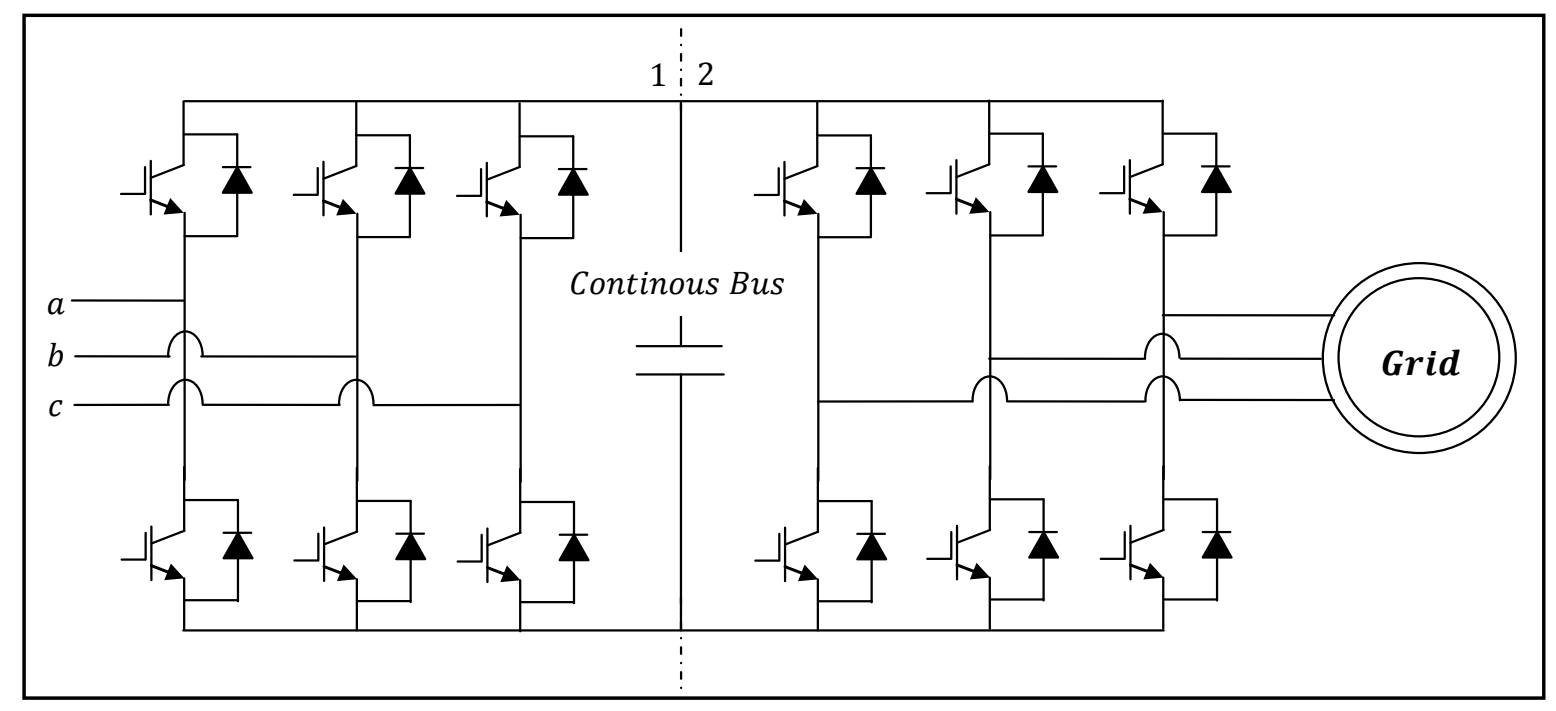

Fig 4 : Back to back converter with transistor half-bridges [22]

Voltage modulation means that the momentary output voltage alters between two well defined voltage levels. A transistor half-bridge represent a switch and a PWM rectifier has three switches. The main objective of the grid-side converter is to control the DC-link voltage. The control of the grid-side converter consists of a fast inner current control loop, which controls the current through the grid-filter, and an outer slower control loop that controls the DC-link voltage. The reference frame of the inner current control loop will be aligned with the grid flux. This means that the ' $q$ ' component of the grid-filter current will control the active power delivered from the converter and the ' $d$ ' component of the filter current will, accordingly, control the reactive power. This implies that the outer DC-link voltage control loop has to act on the ' $q$ ' component of the grid-filter current [23].

The main task of the machine-side converter is, of course, to control the machine. This is done by having an inner fast field-oriented current control loop that controls the rotor current. 
The field orientation could, for example, either be aligned with the stator flux of the DFIG or the grid flux. For both reference frames the ' $q$ ' component of the rotor current largely determines the produced torque while the ' $d$ ' component can be used to control, for instance, the reactive power at the stator terminals [24]. The indices ' $d$ ' and ' $q$ ' indicates the direct and quadrature axis components of the reference frame and the indices ' $r$ ' and ' $s$ ' indicates rotor and stator quantities, $V_{d}$ and $i_{d}$ are the ' $d$ ' components of voltage and current on the AC side respectively, while $V_{q}$ and $i_{q}$ are the ' $q$ ' components of the same. The expression of DC power in terms of ' $d q^{\prime}$ voltages and currents [25].

$$
i_{d c}=\frac{1}{V_{d c}}\left(V_{d} i_{d}+V_{q} i_{q}\right)
$$

The current on the DC side $i_{d c}$ is then given in terms of power on the $\mathrm{AC}$ side and the DC-link voltage $V_{d c}$.

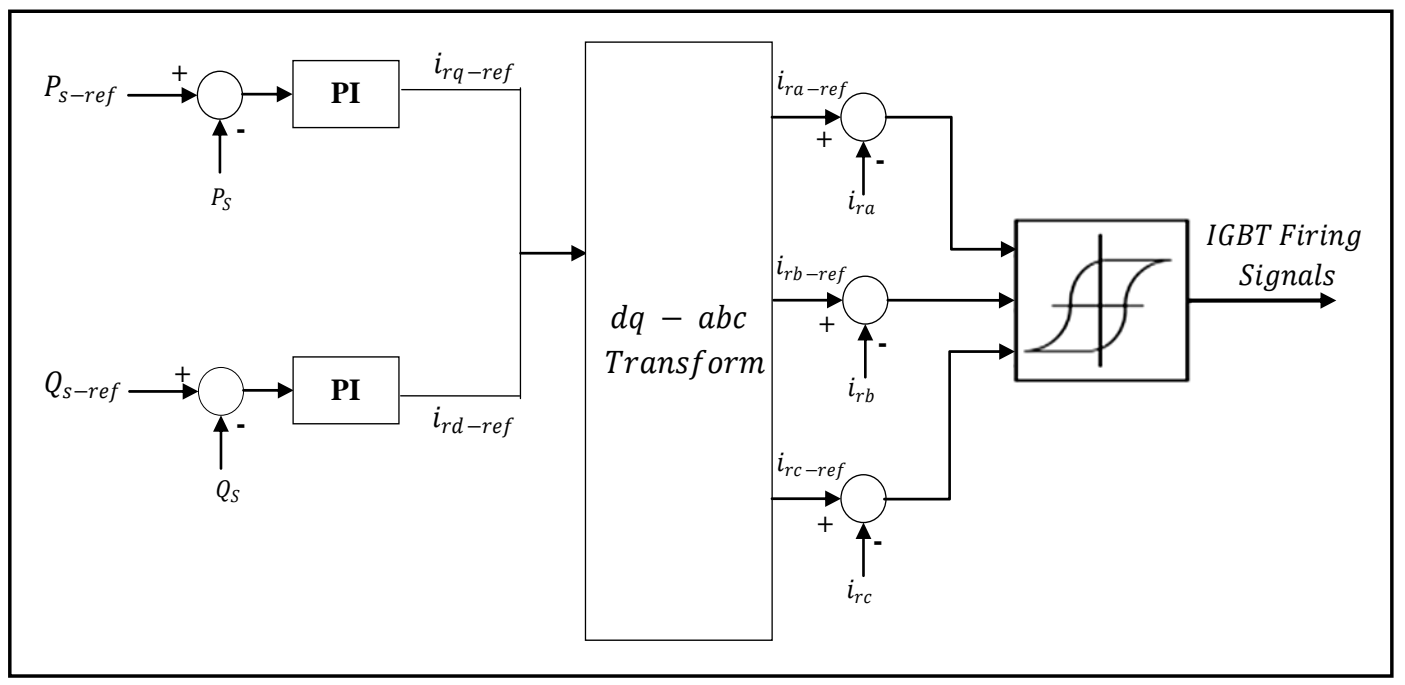

Fig 5 : Command of the DFIG [19]

The active stator power of the generator $\left(P_{S}\right)$ is compared with the reference point value $\left(P_{S-r e f}\right)$ which is determined by the wind speed. The difference between these two values will go to a Proportional Integral (PI) controller, which is used to generate the required value of $q-$ axis rotor current $\left(i_{r q-r e f}\right)$ [11]. Likewise, a PI controller of the reactive power side is used to generate the required $d$-axis rotor current $\left(i_{r d-r e f}\right)$. The two outputs of both PI controllers are transformed from the $q-d$ frame into the $a b c$ frame to obtain the required value of rotor currents. Then, $i_{r a-r e f}, i_{r b-r e f}$ and $i_{r c-r e f}$ are algebraically summed with $i_{r a}, i_{r b}$ and $i_{r c}$ respectively [12]. The last result is obtained because of generation and demand quantities. The triggering pulses would control the IGBT switches in the rotor-side converter and that will enhance the stability of the entire system by sustaining the frequency and voltage within permissible tolerances [19] [20]. The rotor-side converter controller is used to control independently the stator voltage (or reactive power) and output active power of the wind turbine [10] [18]. The generic control loop is illustrated in Figure 5. Since the converter operates in a stator-flux q-d reference frame, the rotor current is decomposed into an active power (q-axis) and a reactive power (d-axis) component. When the wind speed change, the active and reactive (or voltage) power of the generator will also change. On the other hand the role of the grid-side converter is to control the DClink voltage by maintaining it constant and it is also used to generate or absorb reactive power. The DC link voltage is used as well, with the q-d reference frame oriented along the stator currents and stator voltages, enabling independent control of the active and reactive power flowing between the grid and the converters.
Table 1. Parameters of the machine

\begin{tabular}{|c|c|}
\hline Parameters & Values \\
\hline Nominal power & 2,5 MW \\
\hline Nominal voltage & $350 \mathrm{kV}$ \\
\hline Nominal frequency & $50 \mathrm{~Hz}$ \\
\hline Stator inductance & $0.0085 \mathrm{H}$ \\
\hline Rotor inductance & $0.0085 \mathrm{H}$ \\
\hline \multicolumn{2}{|c|}{$V_{d c}: \quad$ DC voltage bus $(\mathrm{V})$} \\
\hline \multicolumn{2}{|c|}{$V_{d c-r e f}:$ DC bus voltage reference $(\mathrm{V})$} \\
\hline \multicolumn{2}{|c|}{ The reactive stator power (VAR) } \\
\hline \multicolumn{2}{|c|}{ The reactive stator power reference (VAR) } \\
\hline \multicolumn{2}{|c|}{ Stator according to q-axis voltage $(\mathrm{V})$} \\
\hline \multicolumn{2}{|c|}{$V_{r d-r e f}:$ Reference voltage following the d-axis $(\mathrm{V})$} \\
\hline \multicolumn{2}{|c|}{$V_{r q-r e f}:$ Reference voltage following the q-axis $(\mathrm{V})$} \\
\hline \multicolumn{2}{|c|}{$P_{S}: \quad$ The active stator power $(\mathrm{W})$} \\
\hline \multicolumn{2}{|c|}{$P_{s-r e f}:$ The active stator power reference $(\mathrm{W})$} \\
\hline$i_{r q-r e f}:$ The rotor current & wing the axis $q(A)$ \\
\hline
\end{tabular}


$i_{\text {ra-ref }}:$ The rotor reference current of the phase a (A)

$i_{r b-r e f}:$ The rotor reference current of the phase b (A)

$i_{r c-r e f}:$ The rotor reference current of the phase c (A)

$i_{r a}: \quad$ The rotor current according to the phase a (A)

$i_{r b}: \quad$ The rotor current according to the phase $\mathrm{b}(\mathrm{A})$

$i_{r c}: \quad$ The rotor current according to the phase c (A)

\section{RESULTS OF THE SIMULATION AND DISCUSSIONS}

The functioning of the complete device was simulated under the environment MATLAB/Simulink for one time of simulation of five seconds (5s) [13].

The strategy of the command introduced previously was tested in the case of variations of the rotor speed. In what follows, the show of the detail of the relative aspects of this strategy and the interpretation of the results of simulation. The strategy of command is based on the indirect command without locking up of power of the DFIG [14] [15].

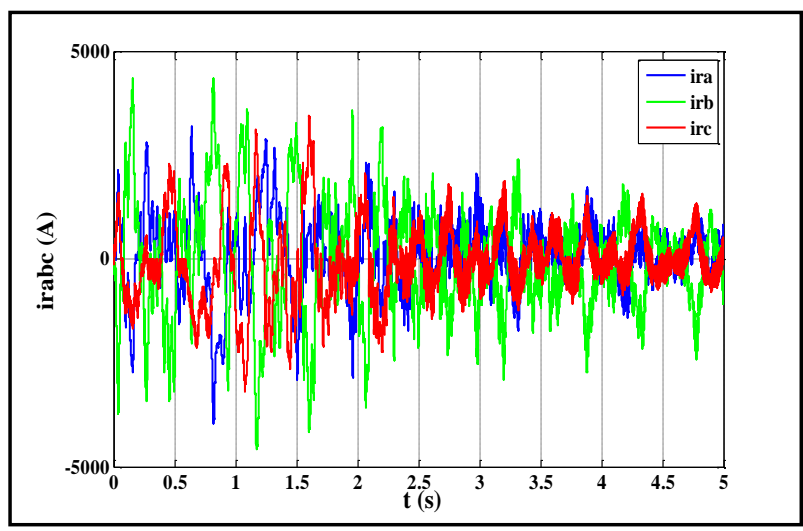

Fig 6 : Rotor current ira (A), irb (A), irc (A) according to time (s)

The rotor current is influenced by the variation of the reactive stator current absorbed by the DFIG, these currents ira (A), irb (A) and irc (A) vary approximately between (-4000A) and $(+4000 \mathrm{~A})$, and they are independent from the profile of wind speed. The rotor currents depend on the variation of the speed of asynchronous machine with double feeding, and on the variation of the sliding of the machine according to the absorption or the supply of the rotor power.

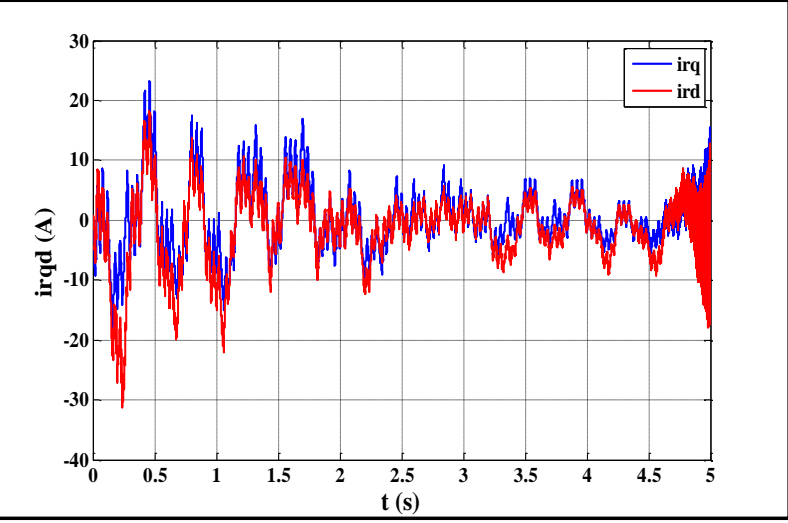

Fig 7 : Rotor current irq (A), ird (A) according to time (s)
These curves show the evolution of rotor currents, these wave forms depend on the speed of the wind. These currents irq (A) and ird (A) vary between $(-32 \mathrm{~A})$ and $(+22 \mathrm{~A})$, and these independent from the profile of wind turbine, these values show that the systems are adapted to high power wind turbine. These currents depend on the active and reactive power.

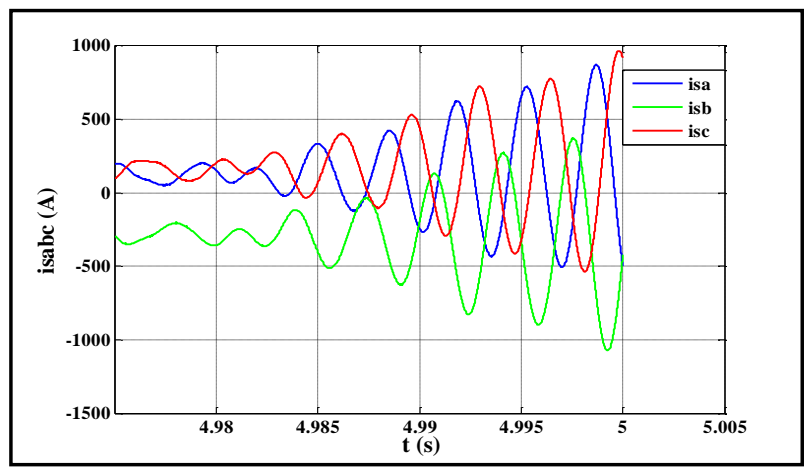

Fig 8 : Stator current isa (A), isb (A), isc (A) according to time (s)

The form of the wave of stator currents is linked to that of the stator active power and of the stator reactive power. These currents vary in sinusoidal forms. The remark is that the currents vary in a sinusoidal manner by increasing their amplitudes. The values of these curves vary approximately between $(-1000 \mathrm{~A})$ and $(+1000 \mathrm{~A})$. These curves depend on the stator flux and stator voltage.

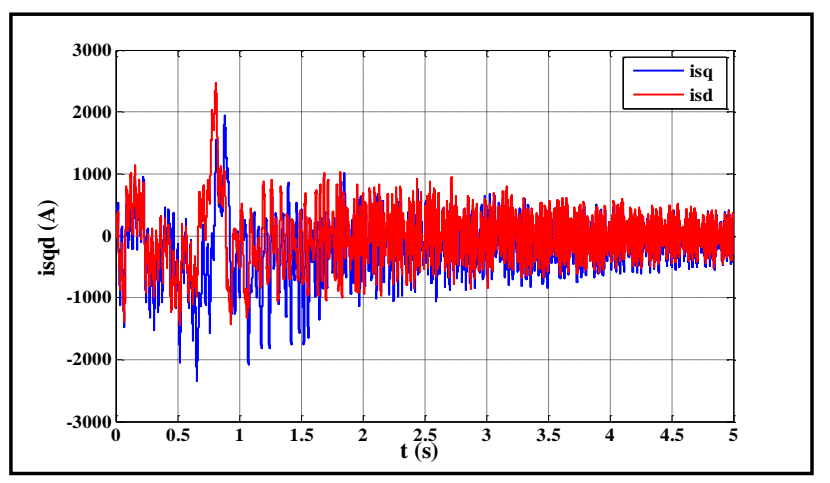

Fig 9 : Stator current isq (A), isd (A) according to time (s)

These currents vary approximately between (-2300A) and $(+2300 \mathrm{~A})$. They depend on the speed of rotation of the machine and show the evolution of the stator active and reactive powers. These currents are independent from the profile of the wind speed.

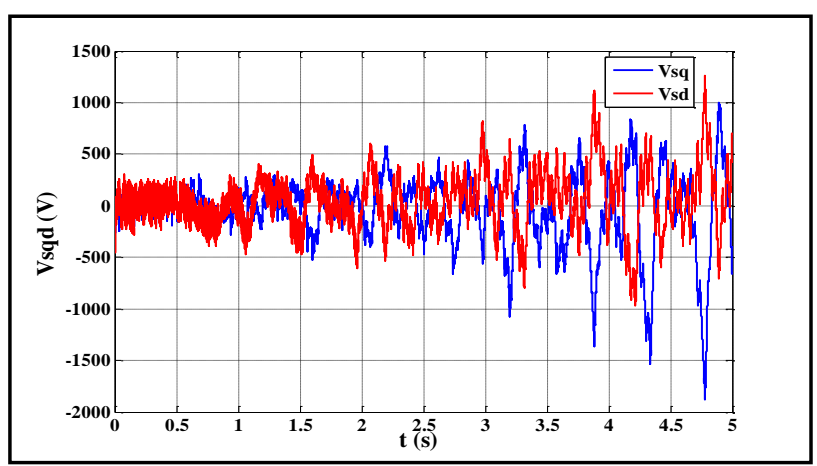

Fig 10 : Stator voltage Vsq (V), Vsd (V) according to time (s) 
The stator voltage depends on the profile of the stator currents isq (A) and isd (A), and it depends on the stator flux $\phi_{d s}(\mathrm{~Wb})$ and $\phi_{q s}(\mathrm{~Wb})$. It should be noted that the wave forms of the tension are independent of the profile of the wind's speed, the forms of waves of the stator tensions are independent, of the speed of wind and they are equal to the tensions of the grid. The stator voltages $\mathrm{Vsq}(\mathrm{V})$ and $\mathrm{Vsd}(\mathrm{V})$ vary between $(-1800$ V) and (1300V).

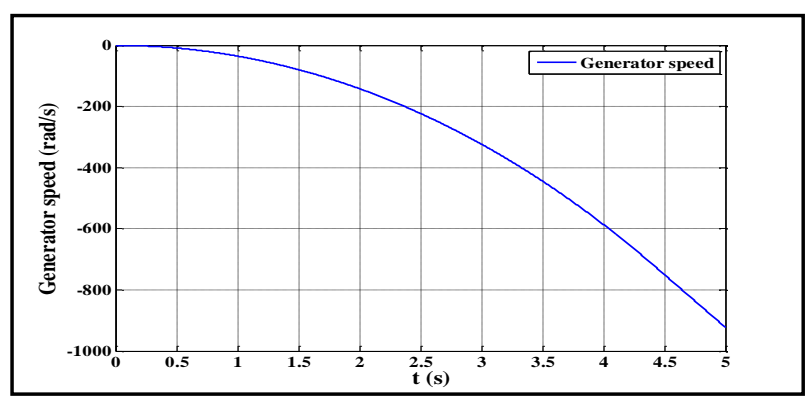

Fig 11 : Generator speed (rad/s) according to time (s)

The generator speed depends on the profile of wind turbine. The values vary between $(-900 \mathrm{rad} / \mathrm{s})$ and $(0 \mathrm{rad} / \mathrm{s})$, and depend on the increase in the speed of its rotation. The mechanical speed on the slow tree multiplied by the coefficient of multiplying leads to a rapid mechanical couple on the asynchronous machine.

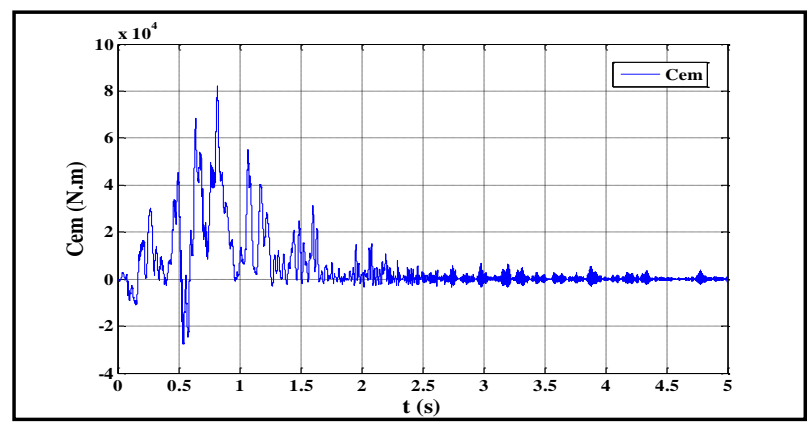

Fig 12 : Electromagnetic couple Cem (N.m) according to time (s)

The electromagnetic couple depend on the evolution of the stator flux $\phi_{s}(\mathrm{~Wb})$, and on the rotor current irq (A). It is independent from the speed of wind, The value of this couple vary approximately between (-30000 N.m) and (+80000 N.m) in the beginning of the simulation and it becomes very adequate to the function of high power wind turbines in the end of the simulation, it fluctuates between 4.98 seconds and 4.99 seconds, and it depends from the stator inductance.

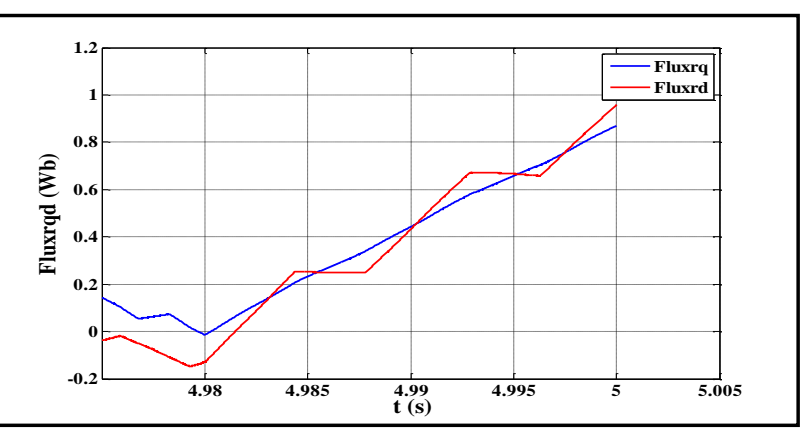

Fig 13 : Rotor flux (Wb) according to time (s)
The rotor flux $(\mathrm{Wb})$ depend on the evolution of the rotor voltage $(\mathrm{V})$. They are independent from the profile of wind speed, and the values of this flux vary approximately between $(-0,15 \mathrm{~Wb})$ and $(0,95 \mathrm{~Wb})$, their shape is appropriate for the stator voltages.

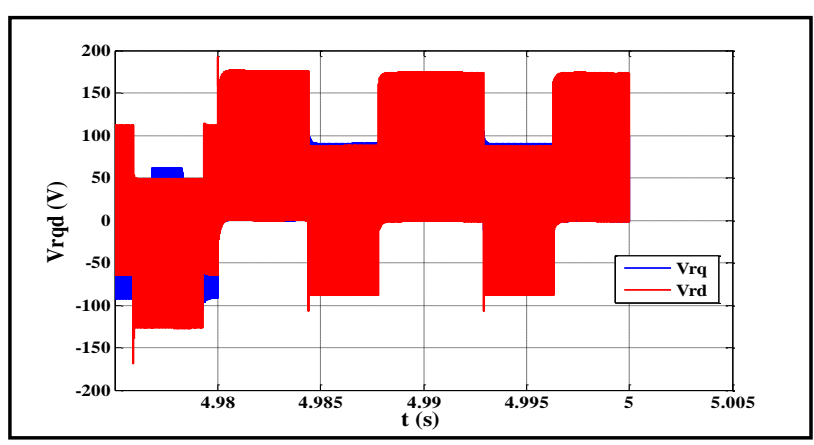

Fig 14 : Rotor voltage Vrq (V), Vrd (V) according to time (s)

This curve shows the evolution of rotor voltages, these wave forms depend on the speed of the wind. They depend on the rotor currents irq (A) and ird (A). The values of these curves vary approximately between $(-170 \mathrm{~V})$ and $(+170 \mathrm{~V})$ in the variable ways, and it depends only from the rotor flux $\phi_{\text {rqd }}$ $(\mathrm{Wb})$. The frequency of rotor tensions depends on the sliding of the machine.

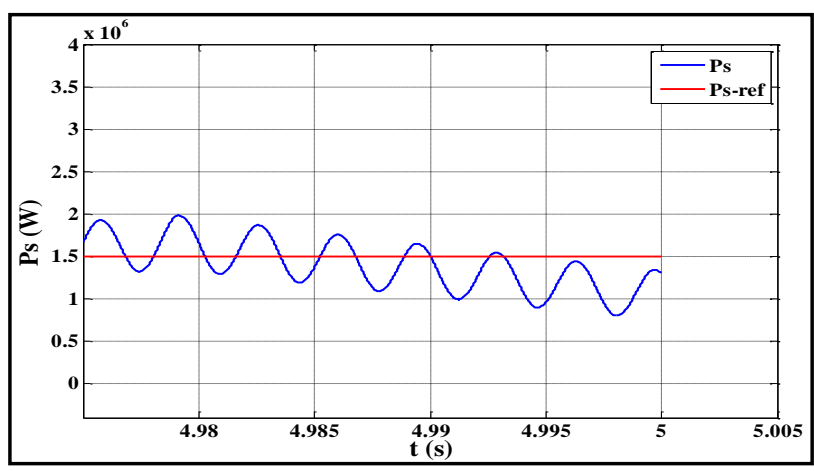

Fig 15 : Active stator power Ps (W) according to time (s)

The active stator power depends on the rotor current iqr (A), and on the stator voltage Vs (V). In addition, it is well controlled by the indirect control in opened loop of the asynchronous machine with double feeding, it varies between $(+0.8 \mathrm{MW})$ and $(+2 \mathrm{MW})$, which is adapted to high power wind turbine, the simulation time is 5 seconds.

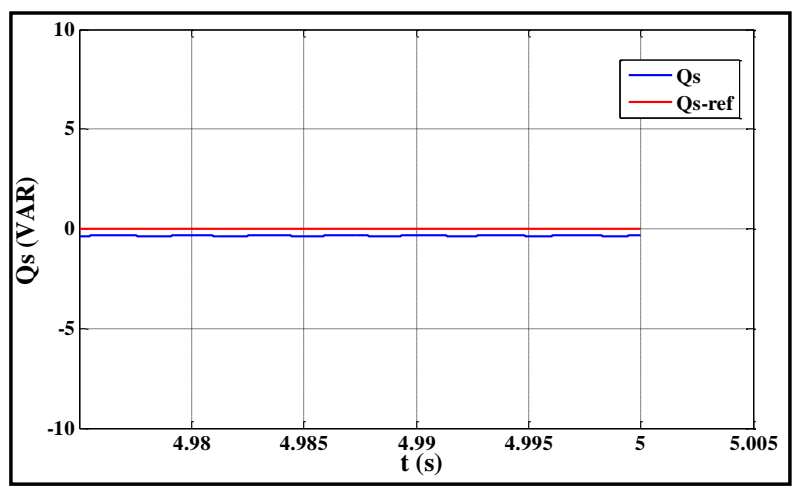

Fig 16 : Reactive stator power $Q_{S}(V A R)$ according to time (s) 
These curves vary between (-0.35VAR) and (0VAR), which shows the robustness of the indirect command of the DFIG used in wind energy and it depends on the rotor current $i_{d r}$ (A), it's independent from the profile of wind turbine, the simulation time is 5 seconds.

\section{CONCLUSION}

The control of the DFIG has been discussed. A review of the component modelling detail required for different study objectives has been provided and appropriate component models are selected [26]. The control design is discussed and the controller performance for power strategies has been discussed and tested by MATLAB/Simulink. This method was demonstrated that it could be used for a DFIG used in wind turbine energy. The algorithm based on a traditional (PI) controller can be used under every circumstance without variations on the control hardware of the actual wind generators. The one based on an indirect opened control presents a better performance for trajectory tracking applications, with error minimisation characteristics but with the need for more computational operations. On the other hand, even if both algorithms present a correct dynamic performance in the developed tests, only the (PI) controller has really been implemented in a wind farm [27]. Thus, it would be interesting to continue analysing the real implementation of the indirect opened control. Finally, as new power regulation systems related to renewable energy sources are being applied in different countries, some research are needed on the generated active power and its quality together with economic aspects of wind farm exploitation. The test bed that has been modelled by using real time digital simulator provides a useful platform for future studies for those who have an interest in wind power and also useful for education and academic works. It can be used to implement and develop various studies such as interaction of wind farm with an energy storage system, interaction of model with a solar system, applying protection system technology and developing new advanced control schemes [28].

\section{REFERENCES}

[1] A. Alesina, M. Venturini, «Intrinsic Amplitude Limits and Optimum Design of 9 Switches Direct PWM AC AC Converter». Proc. of PESC con. pp. 1284-1290, Rec. April 1988

[2] Mister. Budinger, D. Leray, and Y. Deblezer, "Wind turbines and variable speed", The magazine 3EI, flight. 21 , pp. $(79-84,2000)$.

[3] S. HEIER, Grid Integration of Wind Energy, Conversion Systems. New York: John Wiley \& Sons Ltd (1998).

[4] H. Akagi and H. Sato, "Control and performance of a doubly-fed induction machine Intended for a flywheel energy storage system", IEEE Trans. Power Electron., vol. 17, No. 1, pp. 109-116, Jan. 2002.

[5] H. Akagi, Y. Kanazawa, and A. Nabae, "Instantaneous reactive power compensators comprising switching devices without energy storage components", IEEE Trans. Ind. Applicat. vol. 20, no. 3, pp. 625-630, May/June 1984.

[6] J. Bendl, M. Chombt, and L. Schreier, "Adjustable-speed operation of doubly Fed-Machines in pumped storage power plants", in Proc. Ninth International Conference on Electrical Machines and Drives, Sep., 1-3, 1999, pp. 223-227.
[7] S. Bolik, "Grid requirements challenges for wind turbines", in Proc. Int. Work. Large-Scale Integration Wind Power Transmission Networks Offshore Wind Farms, Billund, Denmark, Oct., 20-21, 2003.

[8] M. H. Bollen, Understanding Power Quality Problems : Voltags Sags and Interruptions. Piscataway, NJ, USA : IEEE Press, 2002.

[9] M. Bongiorno, "Control of voltage source converters for voltage dip mitigation in Shunt and series configuration", Chalmers University of Technology, Goteborg, Sweden, Licentiate Thesis 515L, Nov. 2004.

[10] O. Carlson, J. Hylander, and K. Thorborg, "Survey of variable speed operation of wind Turbines", in Proc. of European Union Wind Energy Conference, Goteborg, Sweden, May, 20-24, 1996, pp. 406-409.

[11] L. Congwei, W. Haiqing, S. Xudong, and L. Fahai, "Research of stability of double fed Induction motor vector control system", in Proc. of the Fifth International Conference On Electrical Machines and Systems, vol. 2, Shenyang, China, Aug. 18-20, 2001, pp. 203-1206.

[12] R. Datta and V. T. Ranganathan, "A simple positionsensorless algorithm for rotor-side field-oriented control of wound-rotor induction machine", IEEE Trans. Ind. Electron. vol. 48, no. 4, pp. 786-793, Aug. 2001.

[13] F. B. del Blanco, M. W. Degner, and R. D. Lorenz, "Dynamic analysis of current Regulators for ac motors using complex vectors", IEEE Trans. Ind. Applicat., vol. 35, No. 6, pp. 1424-1432, Nov. /Dec. 1999.

[14] A. Dittrich and A. Stoev, "Grid voltage fault proof doubly-fed induction generator System", in Proc. Power Electronics and Applications (EPE), Toulouse, France, Sep. 2003.

[15] J. B. Ekanayake, L. Holdsworth, and N. Jenkins, "Comparison of 5th order and 3rd order Machine models for doubly fed induction generator (DFIG) wind turbines", Electric Power Systems Research, vol. 67, pp. 207-215, Dec. 2003.

[16] ABB Technical application papers no. 13, "Wind power plants", ABB document 1SDC007112G0201 - 10/2011 4.000 .

[17] C. Hamon, "Doubly-fed Induction Generator Modelling and Control in Dig Silent Power Factory", Master Thesis, KTH School of Electrical Engineering, 2010.

[18] B. Pokharel, "Modelling, Control and Analysis of A Doubly Fed Induction Generator Based Wind Turbine System with Voltage Regulation", Master Thesis, Tennessee Technological University, December 2011.

[19] M. Singh and S. Santoso, "Dynamic models for wind turbines and wind power plants", NREL, Tech. Rep., Oct 2011.

[20] J. Prabhakar and K. Ragavan, "Power Management Based Current Control Technique for PhotovoltaicBattery Assisted Wind-Hydro Hybrid System", International Journal of Emerging Electric Power Systems, 2013.

[21] Seman Slavomir, Antero Arkkio, Julius Saitz, Jouko Niiranen, "Performance Study of a Doubly Fed WindPower Induction Generator Under Network 
Disturbances", IEEE Transactions on energy conversion, vol. 21, no. 4, December 2006.

[22] Carlsson, A. (1998). The back to back converter : control and design. Lund. Department of Industrial Electrical Engineering and Automation. Lund Institute of Technology.

[23] P. C. Krause : "Analysis of Electric machinery" McGraw-Hill Inc, New York, 1994.

[24] Slotine, J.J.E., and Li, W. : "Applied nonlinear control", Prentice Hall, Englewood Cliffs, New Jersey, 1991.

[25] J. Niiranen, "Voltage dip ride through of a doubly-fed generator equipped with an active crowbar", Proceedings of Nordic Wind Power Conference; March 2004.

[26] Abdelhadi EL MOUDDEN, Abdelali AARIB, Abdelhamid HMIDAT : "Optimization of the robust control of the doubly-fed induction generator used in the centralized production of wind energy", The National School of Electricity and Mechanics (ENSEM), Casablanca, Morocco, July 2014.

[27] Abdelhadi EL MOUDDEN, Abdelali AARIB, Aïcha WAHABI, Fatima Ezzahra BOUNIFLI : "Command of the active and reactive stator powers of the doubly-fed induction generator used in wind energy", The National School of Electricity and Mechanics (ENSEM), Casablanca, Morocco ,October 2014..

[28] Mohammad Rashed M.Altimania: "Modeling of doublyfed induction generators connected to distribution system based on eMEGASim ${ }^{\circledR}$ real-time digital simulator", A Thesis Submitted to the Faculty of the University of Tennessee at Chattanooga in Partial Fulfillment of the Requirements of the Degree of Master of Engineering, May 2014.

\section{AUTHOR'S PROFILE}

El Moudden Abdelhadi : Doctor of Science from The National Polytechnic Institute of Toulouse (INPT) in 1993 FRANCE.
He is now a professor in the National School of Electricity and Mechanics (ENSEM), University Hassan II Aïn Chock, Casablanca, Morocco.

Since 2006, he has been a member of Laboratory Computing, Systems and Renewable Energies (LISER), Team Analysis and Command of Electrical Energy Systems (ACSEE). His research interests include Dynamic Simulations of Electric Machinery, Simulation and Optimization of Renewable Energy Systems. He has presented and published many articles in scientific journals and conferences.

Aarib Abdelali: I am in the process of preparing a doctoral thesis in the National School of Electricity and Mechanics (ENSEM), University Hassan II Aïn Chock, Casablanca, Morocco.

Team Analysis and Command of Electrical Energy Systems (ACSEE) - Laboratory of Computing, Systems and Renewable Energy (LISER).

On July 2011 I got a diploma on Master specialized in renewable energy and energy systems in the Faculty of Science Aïn Chock, University Hassan II Casablanca, Morocco. My doctoral thesis discusses the optimization of the electrical energy produced by the double-fed asynchronous machine used in wind power. I presented many communications at international scientific conferences. I attended several international scientific congresses and I participated in the publication of numerous articles in scientific journals.

Hmidat Abdelhamid : Doctorate of 3rd cycle in electric engineering.

Since 1986 he is professor in the National School of Electricity and Mechanics (ENSEM), University Hassan II Aïn Chock, Casablanca, Morocco.

Since 2006, he has been a member of Research Group: Electrical Systems Team.

His research interests include Dynamic Simulations of Electric Machinery, Simulation and Optimization of Resonant Converters. He has presented and published many articles in scientific journals and conferences. 